\title{
Munchausen syndrome by proxy
}

\author{
ROY MEADOW
}

Department of Paediatrics and Child Health, St James's University Hospital, Leeds

SUMMARY Information is presented about 19 children, under age 7 years, from 17 families, whose mothers consistently gave fraudulent clinical histories and fabricated signs so causing them needless harmful medical investigations, hospital admissions, and treatment over periods of time ranging from a few months to 4 years. Episodes of bleeding, neurological abnormality, rashes, fevers, and abnormal urine were commonly simulated. Often the mothers had had previous nursing training and some had a history of fabricating symptoms or signs relating to themselves. Two children died. Of the 17 survivors, 8 were taken into care and the other 9 remained at home after arrangements had been made for their supervision. Study of these children and their families has enabled a list of warning signs to be compiled together with recommendations for dealing with suspected acts. The causes and the relationship of this form of behaviour to other forms of non-accidental injury, iatrogenic injury, and parental-induced illness are discussed.

The label Munchausen's syndrome was devised by Richard Asher to describe patients who consistently produce false stories and who fabricate evidence so causing themselves needless medical investigations, operations, and treatments. ${ }^{1}$ It has become a wellknown condition and can sometimes affect older children. ${ }^{2} 3$

The children described have parents who, by fabrication, have caused them innumerable harmful medical procedures-a Munchausen syndrome by proxy.

Since details of 2 such families were published in $1977^{4}$ I have encountered 2 more families and I have been told of several similar cases by other paediatricians. Details on 19 children have been collected from 17 families with the aim of studying the characteristics of the syndrome and of finding features which may aid early detection and help for the families.

\section{Methods}

The children are ones for whom there was clear evidence of massive and persistent fabrication by a parent of both the history and the signs. Cases of suspected or mild fabrication are not included, nor are the slightly more common instances of children who were poisoned by a parent. However if poisoning occurred as well as other fabricated acts by the parent the child is included.

Three other clear cases of Munchausen syndrome by proxy are excluded because records were not sufficiently detailed.

The information on 4 children, each from a different family, was obtained from my own records and from the notes of the hospitals and referring doctors. The other 15 children were notified to me by other paediatricians in England. Further details of the events, the children, and the families were obtained by correspondence, a questionnaire, and a study of medical notes and hospital records. The considerable detail obtained is a reflection of the time and trouble taken by the paediatricians. Some of these children have been the subjects of short reports or of correspondence in medical journals. ${ }^{5-8}$

The enquiry considered the following aspects: the child, the 'illness' and its perpetration, the consequences and outcome, and the parents. In most cases full details were available for each aspect; in a few information was not sufficient for a particular aspect and so was omitted. Thus the results refer to all 19 children and all 17 families except in instances in which the group total is specified as being smaller than the full number.

\section{Results}

\section{Features of Munchausen syndrome by proxy.}

\section{The child and the illness}

The 19 children, 10 boys and 9 girls, come from 17 families. By the time the deception was revealed the 
ages of the children ranged from 4 months to 7 years (mean age 3 years 2 months).

The children had had a plethora of serious symptoms and signs. Generally the features suggested a multisystem disorder, although in a few the features were limited to one system-for example the urinary tract. The false symptoms and signs had persisted or recurred for an average of 13 months (range $1 \frac{1}{2}$ months to 4 years) until the moment of revelation, after which they stopped. The principal signs are listed in Table 1.

Most of the children had been seen by many different doctors, and had been referred from hospital to hospital for additional specialist advice. One had been examined by 28 different consultants. Although the initial reported symptoms and signs were false most of the children incurred secondary symptoms and signs as a result of investigations, operations, and medications. During their 'illness' many different diagnoses had been considered. Table 2 lists the diagnosis that was con-

Table 1 Nature and incidence of fabricated signs in 19 children

\begin{tabular}{ll}
\hline Fabricated sign & No of children \\
\hline Bleeding & 12 \\
$\quad$ Haematuria $\mathrm{n}=7$ & \\
Haematemeses $\mathrm{n}=5$ & \\
Haemoptyses $\mathrm{n}=3$ & \\
Blood in faeces $\mathrm{n}=3$ & \\
Epistaxes $\mathrm{n}=1$ & \\
Neurological & 7 \\
$\quad$ Drowsiness/coma $\mathrm{n}=5$ & \\
Seizures $\mathrm{n}=3$ & \\
Unsteadiness $\mathrm{n}=2$ & \\
Rashes & 6 \\
Glycosuria & 5 \\
Fevers & 4 \\
Biochemical chaos & 4 \\
Faeculent vomits & 2 \\
\hline
\end{tabular}

Table 2 Diagnosis that was considered most likely in 14 children immediately before the deception was revealed. (Porphyria and dermatitis herpetiformis were earlier, or additional secondary, diagnoses)

Provisional diagnosis

Chronic granulomatous disease

Diabetes mellitus

Encephalopathy

Leigh's encephalopathy

Grand-mal epilepsy

Pituitary disorder

Pulmonary haemosiderosis

Renal tubular dysfunction

Nephritis

Polyarteritis nodosa

Ulcerative colitis

Food intolerance

Recto-vesical fistula

Osteomyelitis

+ Porphyria $(n=4)$

Dermatitis herpetiformis $(n=4)$ sidered most probable in the week before deception was revealed. Dermatitis herpetiformis and porphyria had been considered in many as a secondary additional diagnosis.

The perpetration. In each case the mother was the source of the fraudulent history and the fabricator of false signs. Generally most harm to the child was done by doctors who were investigating or treating the false illness. In a few cases the mother herself was concerned in directly harmful activity too-for example by giving a poison or scratching the child's skin.

The false histories were impressive in their medical detail and the fabricated signs were realistic. The methods combined cunning, dexterity, and, quite often, medical knowledge.

Bleeding was generally the result of the mother adding her own blood to the child's vomit, urine, or faeces. Sometimes blood was smeared on a young child's face or perineum. The blood was usually obtained by the mother pricking herself but one mother used blood from an open thigh wound. Another mother stirred a vaginal tampon (during menstruation) in the child's urine specimen. A few mothers simulated blood in a specimen from the child by adding paint, cocoa, or phenolphthalein.

Faeculent vomitus was produced by a resident mother who kept in her cubicle a container of soft faeces which she mixed into the child's vomit.

Fevers were produced by rubbing thermometers or immersing them in hot liquids.

Biochemical chaos arose from either diluting or adding chemicals-such as salt- to blood specimens. While the specimen was being altered a variety of tricks was used to distract the doctor who had taken the blood specimen.

Rashes were fabricated in three main ways. (1) By rubbing the skin gently and repetitively with a finger nail or sharp object to obtain a bullous lesion 'dermatitis herpetiformis'. (2) By applying caustic solutions to small areas of skin. (3) By painting with a dye-such as phenolphthalein.

The neurological features were generally the result of the mother giving sedatives or tranquilisers which had been prescribed for herself, to the child. They were given in doses greater than those prescribed for the mother. One mother applied pressure to the child's neck (carotid sinus pressure) to cause the child to have seizures.

The consequences. All the children suffered needlessly, incurring long stays in different hospitals together with painful and damaging investigations and harmful treatments. One 6-year-old boy incurred 13 
months away from school, 5 months in hospital, 1 month of intravenous fluids, and the following procedures: barium meal (2), intravenous urogram, skeletal survey, brain scan, lumbar puncture (2), electroencephalogram (2), biopsies of bone, kidney, and the skin. In addition he had endoscopy of upper gastrointestinal tract, and more than 120 venepunctures.

During the same period he was prescribed and given the following drugs for the alleged illness: prednisolone, hydrocortisone, ACTH, intravenous methylprednisolone, cyclophosphamide, azathioprine, ampicillin, penicillin, cephaloridine, erythromycin, co-trimoxazole, fusidic acid, cimetidine, metoclopramide, propantheline, prochlorperazine, trimeprazine, chlorpromazine, trifluoperazine, hydralazine, methyldopa, frusemide, naproxen, aspirin, paracetamol, pethidine, and phenylbutazone.

At the time the deception was revealed he was being considered for plasmaphoresis.

Final outcome. Seventeen of the 19 children survived and are well. Two died, one from presumed poisoning and another in uncertain circumstances while abroad. Of the 17 survivors, 8 were taken away from the family into care. Nine remained at home after confrontation with the parents, involvement of the social services, and arrangements for continuing supervision. Seven of these 9 children were known to be well and free of all symptoms at follow-up 1-4 years later. Two children continued to be taken by their mothers to a variety of doctors because of apparently minor complaints, but neither gross nor harmful fabrication was taking place.

The parents. Fifteen of the 17 pairs of parents were living together. Their mean age was 29 years (range 24 to 37 ) at the time the fabrication was discovered.

The present or past occupation of 16 culprit mothers was nurse $(n=8)$, paediatrician's receptionist $(n=1)$, home-help $(n=1)$, primary schoolteacher $(n=1)$, baby-food demonstrator $(n=1)$, no regular paid employment $(n=4)$. Only one of the 8 nurses was a fully qualified state-registered nurse. Most of the others had begun training but had abandoned the course because of examination failure. Several had, nevertheless, been able to gain employment with nursing duties.

Seven of 12 mothers had a history suggesting that they, themselves, had some features of Munchausen's syndrome. In 4 mothers these features were slight, but in 3 they were pronounced and persistent. Verity et al. described the children of one of these mothers as suffering from Polle's syndrome ${ }^{7}$ (Polle being the child of Baron Von Münchhausen who died at age 1 year).

Five of 10 mothers each had a history within the previous 3 years of symptoms and signs similar to those which she fabricated for the child. Often their own symptoms had been dealt with somewhat cursorily by their doctor. An example was a mother with dysuria and haematuria who substituted her urine for the child's and caused her child to have the radiological and other investigations which might have been appropriate for herself.

Most of the mothers either lived in hospital with the child or visited it for long periods each day. Fourteen mothers were noted to be particularly attentive to the child. Characteristic comments from the paediatric staff included 'the mother was like a limpet', 'she would never leave the ward, even for a meal', and 'the mother stayed in hospital for 4 weeks and never once went outside'. Many of the mothers seemed to enjoy the prolonged stays and formed close relationships with the junior doctors and other resident parents. Many of the staff were pleased and flattered by the mothers' complimentary remarks about the standard of care.

The fathers kept a low profile. Ten out of 15 rarely visited the children in hospital; this was particularly noteworthy in view of the severity of the children's illness. Six of 11 had jobs which caused them to be away from home for long periods or in the evenings, and 2 others were considered extremely unsupportive to their wives for other reasons. The fathers did not appear to know of the fabrication and had difficulty in believing it when told.

In 10 of 15 families there was a greater than usual discrepancy between the social or the intellectual grade of the parents. In each the wife either came from a higher social background or seemed much more intelligent than her husband. In 2 families the wife's 'superior' status was such that her parents had ceased to communicate with her or her husband on marriage.

In 15 of the 17 families there were other children. In 2 families a second child incurred Munchausen syndrome by proxy, and it is probable that an earlier prolonged mystery illness in an elder sibling was another example in a third family. In one family a sibling had suffered non-accidental injury, and in another a younger child had died in suspicious circumstances. But in $\mathbf{1 0}$ families there was nothing to suggest injury or mischief to either older or younger siblings.

\section{Discussion}

The children reported have suffered greatly from 
their mothers' behaviour and the doctors' responses. Three aspects deserve particular consideration as a better understanding may lessen the chance of harm to children. (1) Ways of detecting the fabricated happenings earlier-that is warning signals. (2) Prompt and effective action once the syndrome is suspected. (3) The behavioural cause.

Warning signals. Munchausen syndrome by proxy affects children under age 6 years. After that age the child would be likely to reveal the deception. The more common methods of fabrication are shown in Table 1 , but the possibility of fabrication needs to be considered in any young child who has: (1) persistent or recurrent illnesses which cannot be explained; (2) investigation results and signs which are at variance with the general health of the childfor example fevers or blood loss when the child neither looks ill nor as if he is bleeding. In such children there is a discrepancy between the clinical findings and the history, and the symptoms and signs do not make clinical sense; (3) worrying symptoms and signs which cause experienced specialist doctors to remark that they have 'never seen a case like it before'; (4) symptoms and signs which do not occur when the child is away from a parent (the mother); (5) any mother who is particularly attentive in prolonged visiting, or living in hospital with her child, and who refuses to leave the child alone in the hospital ward even for an hour; (6) treatments that are not tolerated: sticking plaster or local treatment causing an 'allergic rash', intravenous drips that keep coming out, inability to tolerate any prescribed drug treatment because of vomiting; (7) a very rare disorder: Munchausen syndrome by proxy is less rare than certain notorious disorders - for example porphyria (for which several of the children had been investigated); (8) any mother, who despite her child's fearful problems, does not seem as worried about her child as are the medical and nursing staff. (When I was particularly upset and desperate because of failing to resolve the problems of one child, her mother sat me down, gave me a cup of tea, and told me how she admired me for trying so hard and that I 'must not worry so much'); (9) 'seizures' that do not respond to carefully administered anticonvulsants.

The presence of any of these is especially suspicious if the mother has had previous medical or nurse training, or a history of similar illness herself.

Action. Although as doctors we must continue to behave as if the mother's story of her child is accurate, we must remember that sometimes the story is false. We need to have a small degree of suspicion always.
If fabrication is suspected: (1) The child must be separated from the mother to find out if the symptoms and signs occur in her absence. If necessary a place of safety order should be considered, and it is likely to be helpful to make contact with the social services department early. Arrangements must be made for an experienced nurse to collect and guard all specimens destined for laboratory investigation.

(2) Check all the details of the history relating to the child, the family, the mother and her life. The general practitioner, health visitor, persons in other hospitals, and the mother's past employers will be useful sources of information. It is common for the fabrication to extend beyond the child's illness and for details of the mother's schooling, employment, and life to be false also. Check if the mother has fabricated symptoms relating to herself and if she suffers, or has suffered, from the symptoms and signs she has donated to the child.

(3) Check the story for a temporal relationship between symptoms, signs, and the parents' presence.

(4) Keep specimens for detailed investigation. Collect them on admission and whenever the child is 'ill' or the symptoms recur. For toxicological assay large volumes may be needed-for example at least $50 \mathrm{ml}$ urine collected in a container without added preservative, and $10 \mathrm{ml}$ blood in a heparinised tube. Complete samples of vomit should be saved. A useful toxicological screening programme has been outlined by Rogers et al. in relation to deliberate poisoning of children. ${ }^{9}$

(5) Check and check again the reliability of the signs. Check that the rash does not wash off with water or spirit, that the blood really is blood and that it is the child's. A local haematology or blood transfusion laboratory may be able to differentiate blood of the child from that of the mother but the police regional forensic laboratory will be accustomed to this sort of work and has more sophisticated techniques.

(6) Enrol psychiatric help (I regret putting this as a low priority; but in relation to the cases in this paper psychiatric help seems to have been of limited value).

Once the suspicion is confirmed the plan of action is similar to that for a child with non-accidental injury. It has to be decided if the child should be removed from the family, or can remain there under supervision. Of the children reported, 9 of the 17 surviving children continued to live at home and have progressed satisfactorily. In some cases the child would not have been allowed to stay at home had the forensic evidence been sufficient to make certain of a court care-order for removal of the child.

Eight of the children were taken into care, and all 
except 2 of the remaining families were confronted with their deception. But the extent of the confrontation varied. In some instances the doctor told the mother that her deception had been uncovered, and that if further deception occurred the police might be called in. In other cases the doctor told the parent that since the child was coming to harm in his present environment the social services had been requested to keep a check on the child and to advise whether the child would be healthier and safer elsewhere. In several cases the management was complicated by the fact that the deception was uncovered in a regional centre to which the child had been referred from a peripheral unit. The continuing management and supervision was sometimes entirely based on the peripheral unit.

After confrontation the troubles ceased. One of the 2 children who died had gone back to a mother who was not confronted directly. In that case those who referred the child doubted our findings and conclusions, and though I thought that the mother suspected that we knew of her deception there was no direct confrontation. The mother and child returned to their home town where further investigations were undertaken. When the child died (probably poisoned) the mother wrote a letter thanking me 'for understanding' and then took an overdose. My sense of failure led me to favour direct confrontation, and in 2 subsequent instances I have told the mother that I knew and understood what she is doing. Neither mother has admitted it nor has she specifically denied it. Her response has been 'Why on earth would I do that ?'. However, the troubles have stopped and the children have made miraculous recoveries. With one of these families the social services and the police were involved and the mother greets me in a very superficial and evasive way when the child is brought for regular checks. With the other family outside agencies were not needed and the family doctor now supervises the family. The children are growing up healthily. The mother has told false stories to the neighbours about the cause of her daughter's long illness and the nature of the cure in Leeds. She wrote recently 'I will forever thank God and you'. Nevertheless the fact that confrontation has produced apparent cure in some cases does not ensure that it will always achieve that, nor does confrontation necessarily resolve what must be an extremely disturbed and complex mother-child relationship.

The behavioural cause. The result for the children was non-accidental injury, yet these children and families differ in several ways from the more common cases of non-accidental injury in our region. The parents are older and there is not the usual preponderance of social classes IV and $\mathrm{V}$ families living in poor homes. The cases are more similar to deliberate poisoning of a child by a parent, and in some of the cases reported in this paper poisoning was one of the several actions taken by the mother. The possible reasons for parents poisoning their children have been well discussed..$^{910}$

It would be naive to seek a single cause for the harmful behaviour of these mothers. For some the child's illness brought about a closer relationship with the husband; for others it seemed to provide welcome distraction from personal and home difficulties. Several of the mothers thrived on the children's wards. They seemed to love it, bustling round helping other mothers, helping the nurses, and forming close relationships with the junior medical staff. They made the medical staff feel that the paediatric service was really good! For the 3 mothers who themselves had marked Munchausen's syndrome the abnormal behaviour at first spilt over and then engulfed the child.

For some it seemed to be a bizarre game in which they matched themselves against the best specialists and the best hospitals they could find. As one problem was resolved another would be created. The common nursing and medical background was privileged information for the game they created. They knew the rules, and also the stereotyped responses of doctors. Most of the ex-nurses had failed their course; it could be suggested that some were determined to defeat the system that had defeated them. The preponderance of nurses and the way in which some of the mothers thrived while resident on a good paediatric ward lends support to the adage that the desires to nurse and be nursed are closely linked. It is relevant that adults who indulge in self-mutilation and deliberate disability often have been nurses. ${ }^{11}$ Therefore, it seems that nurses and former nurses are at risk for damaging themselves and their children with the result that either they or their children incur needless hospital admissions and investigations.

Most of the mothers seemed caring and loving with their children. They did not appear cruel, negligent, or uncaring. It was not possible to obtain details of early experiences and family life for each mother, but for those for whom such information was available there seemed no excess of deprivation or institutional life. Moreover, those mothers who were referred to a psychiatrist tended to emerge without a diagnostic label; this is presumably a reflection of the difficulty of defining normal and abnormal personality for we would all agree that the mother's behaviour had been abnormal.

It was the doctors who injured the children the ons 要

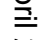
满 N , $\omega$ פ . . 해유 
most. Doctors behave in stereotyped ways-a symptom or sign is matched by an investigation or treatment. We still behave as if missing an organic cause for a complaint is the greatest sin. It is not. It is far worse to batter a child to near death with investigations and treatment when the problem is the mother's behaviour. We should develop broader shoulders on which to bear the knowledge that we might miss some organic diagnoses, learn to tolerate uncertainty and unresolved problems, and remember the vista of behavioural variation. This need is as great, if not greater, for child psychiatrists as it is for paediatricians.

Many mothers exaggerate the details of their children's illness to ensure more prompt or better medical help. Is Munchausen syndrome by proxy one end of that spectrum? It may be so, for some of the actions described in this paper share similarities with the many less striking and more common cases one encounters: mothers who seem reluctant to let their children grow up and be independent, who keep them away from school for long periods because of colds, headaches, or some minor symptom, or who continually remind their children of symptoms which if left unmentioned would soon be forgotten. Eisenberg has referred to the masquerade syndrome in which mothers use small childhood complaints to keep their children at home. ${ }^{12}$ Such childhood complaints seem minor to the doctor and he may miss the fact that they are a masquerade for the real problem of prolonged school absence. Most of us are familiar with those mothers; to me they have seemed extremely similar in personality and behaviour to the mothers in Munchausen syndrome by proxy. With older children there is often some complicity between mother and child and one of them initiates the deception while the other helps it to persist. Similarly there is likely to be complicity with older children in some cases of Munchausen syndrome by proxy. We strongly suspected this to be the case with a 6-year-old boy, since some of the fabrication could not have been achieved by the mother without his assistance.

How common is Munchausen syndrome by proxy? It is certainly more common than reports suggest. Six of these children are from Yorkshire and so the number of cases occurring in Britain during the same period is likely to be at least 60 . Moreover, recent reports from America confirm that it is not merely a British disease. ${ }^{13-15}$ Goethe wrote 'We see only what we know'. As doctors we recognise only what we know to be possible. Now that we know Munchausen syndrome by proxy exists we may recognise it more readily.

The doctors who have encountered these families will not forget them. Most of us will feel saddened and perhaps ashamed of our repeated investigational and therapeutic assaults on the children, the result of us following our usual practice of trusting the mother and trying to help. The cases will stand out in our memories like warning beacons and should help us to detect the rare cases of deliberate deception faster. The same warning beacon should also illuminate and remind us of the thousands of children who undergo unpleasant investigations because of behavioural problems that have not been identified, and the multitude who have unnecessary operations to remove appendices, tonsils, adenoids, and foreskins, because parents exert pressure which doctors fail to resist.

In recognising that a few mothers, by extreme fabrication, lead us to harm healthy children with our management, we should also become more aware that, even when the parents and doctor have great integrity, the potential hazards of our management for children with common problems are considerable.

\section{Addendum}

Since this paper was accepted for publication I have been informed by paediatricians of 6 more English children who have suffered Munchausen syndrome by proxy. In one case the parents were the chief fund raisers for the paediatric unit; hospitals can be a strong (and dangerous) addiction. I remain interested in hearing about other new cases.

\section{$\mathbf{R} \mathbf{M}$}

I thank the following paediatricians who provided details of these children, their families, and similar cases: W A Arrowsmith, C C Bailey, B D Bower, D Burman, C Chantler, R Counahan, D B Grant, R S Illingworth, A D M Jackson, G M Komrower, D A Lee, J Lorber, D Morris, R J Pugh, J K Sarsfield, J H Tripp, J B G Watson. I am grateful to Doctor Michael Buchanan, Doctor Ian Berg, and Professor Roger Robinson for thoughtful criticism and Mrs Wendy Pearson for secretarial assistance.

\section{References}

1 Asher R. Munchausen's syndrome. Lancet 1951 ; i: 33941.

2 Sneed R C, Bell R F. The Dauphin of Munchausen: factitious passage of renal stones in a child. Pediatrics 1976; 58: 127-30.

3 Reich P, Lazarus J M, Kelly M J, Rogers M P. Factitious feculent urine in an adolescent boy. JAMA 1977; 238: 420-1.

4 Meadow R. Munchausen syndrome by proxy-the hinterland of child abuse. Lancet 1977; ii: 343-5.

5 Lorber J, Reckless J P D, Watson J B G. Non-accidental poisoning; the elusive diagnosis. Arch Dis Child 1980; 55: 643-7. 
${ }^{6}$ Clayton P T, Counahan R, Chantler C. Letter: Munchausen syndrome by proxy. Lancet 1978 ; i: 102-3.

7 Verity C M, Winckworth C, Burman D, Stevens D, White R J. Polle syndrome: children of Munchausen. Br Med J 1979; ii : 422-3.

8 Lee D A. Munchausen syndrome by proxy in twins. Arch Dis Child 1979; 54: 646-7.

- Rogers D, Tripp J, Bentovim A, Robinson A, Berry D, Goulding $R$. Non-accidental poisoning: an extended syndrome of child abuse. $\mathrm{Br}$ Med J 1976; i: 793-6.

10 Watson J B G, Davies J M, Hunter J L P. Non-accidental poisoning in childhood. Arch Dis Child 1979; 54: 143-4.

11 Hawkings J R, Jones K S, Sim M, Tibbetts R W. Deliberate disability. $\mathrm{Br}$ Med $\mathrm{J}$ 1956; i: 361-7.

12 Waller D, Eisenberg L. School refusal in childhood-a psychiatric-paediatric perspective. In: Hersov L, Berg I, eds. Out of school. Chichester: Wiley, 1980: 209-29.
13 Fleisher D, Ament M E. Diarrhea, red diapers, and child abuse. Clin Pediatr (Phila) 1977; 17: 820-4.

14 Kohl S, Pickering L K, Dupree E. Child abuse presenting as immunodeficiency disease. $J$ Pediatr 1978; 93: 466-8.

15 Kurlandsky L, Lukoff J Y, Zinkham W H, Brody J P, Kessler R W. Munchausen syndrome by proxy: definition of factitious bleeding in an infant by ${ }^{51} \mathrm{Cr}$ labeling of erythrocytes. Pediatrics 1979 ; 63: 228-31.

Correspondence to Professor S R Meadow, Department of Paediatrics and Child Health, St James's University Hospital, Leeds LS9 7TF.

Received 2 February 1981 